Quando Ruy foi preso por motivos políticos e mantido incomunicável por vários dias, em 1970, criou-se entre os parentes e amigos uma expectativa pesarosa. Coitado do Ruy, tão gentil, tão afeiçoado às leituras noturnas, à música, ao conforto doméstico, como deve estar sofrendo! Depois, por vias subterrâneas, chegou aos irmãos um bilhetinho secreto. Todos respiraram. Ruy pedia que lhe mandassem as obras completas de Proust. A primeira visita dissipou qualquer dúvida. Ruy insistiu em que ninguém se preocupasse com ele. A vida na prisão, acentuou, não diferia muito da que sempre levara. Continuava lendo, conversando, dando aulas, organizando cursos. De vez em quando, interrogado, discutia marxismo com tenentes e majores que certamente não sabiam com quem estavam se metendo.

Ora, curiosamente, esse distanciamento, que não significava nem indiferença pelas pessoas nem alheamento político (caso contrário, não teria sido preso), foi o que propiciou a sua ascensão na hierarquia universitária. Nunca foi propriamente (ou mesmo impropriamente) um administrador. Mas para isso já existia na Faculdade de Filosofia um mecanismo bem montado, com funcionários experientes que, se já não eram, logo se tornaram seus amigos. A real dificuldade estava na Congregação, onde se batiam e se defrontavam, como de costume, interesses e tendências divergentes. $E$ foi aí que Ruy cresceu. Não se envolvendo em questiúnculas pessoais, não tendo vaidade nem ambição de mando, erigiu-se naturalmente numa instância superior em que todos confiavam. Distraído em relação às coisas pequenas - e sobre isso construiu-se através dos anos um pitoresco e afetuoso folclore -, podia dedicar-se, como bom clérigo, aos fins maiores.

A tranqüilidade com que enfrentou a morte confirmou a firmeza já demonstrada em todos os incidentes que cercaram a sua prisão, revelando o que havia de fibra interior em sua personalidade tão amena. Não escondeu nem ostentou a doença, as duas reações defensivas mais freqüentes. $O$ corpo depauperava-se mas a cabeça mantinha-se a mesma, lúcida, isenta. Conversava sobre tudo, menos sobre o seu caso. Contou, no entanto, que estava relendo Proust numa nova edição crítica que acabara de sair na França, pensando em escrever um artigo sobre a sua velha e inextingüível paixão.

Ruy Coelho freqüentou longamente os highlands do pensamento sem nunca se extraviar neles, como temia Mario de Andrade. Mas também não deixou, à margem de sua atividade profissional universitária, a obra de ensaísmo literário de que era capaz e que esperávamos dele. Talvez por falta de ambição, parecia contentar-se nesse campo com a oralidade, como disse nas entrelinhas ao agradecer a homenagem que há poucos anos lhe prestou a Faculdade de Filosofia. Com isso perdemos nós, perdeu a literatura. Mas nunca ninguém lhe tirará as horas extras de prazer que ganhou ao deixar de escrever, dedicando-se à leitura da imensa legião de livros que num certo dia - ou, mais provavelmente, numa certa noite - despertaram-lhe a universal e voraz curiosidade. Pensar fascinava-o mais que passar as idéias ao papel, embora o fizesse com facilidade quando preciso. Em meio à feira de vaidades literárias talvez seja essa a mais modesta e requintada forma de sabedoria.

\section{Os limites da catástrofe}

JERUSA PIRES FERREIRA é professora da ECA-USP e trabalha com temas medievais e populares. É autora de Cavalaria em cordel (Editora Hucitec) e O livro de Sáo Cipriano - uma legenda em massas (a sair em breve).

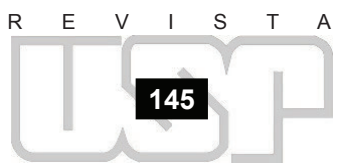


cioso. Depois, se chegava aos olhos apertados, ao riso, quase máscara, dando lugar ao sorriso gentil, à finura expressa. $\mathrm{O}$ andar de um lado para o outro, o paletó de tweed, a blusa de golinha roulé o vestiam, e ele, pensando e sem poder interromper aquela torrente de associações e imagens tangenciais, parecia buscar no infinito a palavra desgarrada, o acorde fugidio, a música dos anjos, a perdição dos demônios. Tudo sempre do mesmo modo, como se ele próprio vestisse a túnica inconsútil, como se houvesse algo a explicar e que não coubesse em nenhum dos parâmetros das ciências conhecidas. Era então que o paradoxo acudia, o jogo da linguagem e dos contrários nos instalava para além do бbvio: "É mais fácil para um homem da Idade Média recusar a idéia de Deus do que para um homem do Renascimento"*... e passava daí aos labirintos e subterrâneos, fazendo-nos seguir os percursos de um Pico de la Mirandola, de um Giordano Bruno.

Eu chegava a São Paulo, carregada de aturdimentos, assustada pela perda de nexos, e então o alumbramento de encontrá-lo, de volta do prolongado exílio. Era o ano de 1977. Falaria dos mesmos temas que eu estudava, da Princesa Longínqua ou de Isolda das Brancas Mãos, transitando entre as personagens de Chrétien de Troyes, as evocações mágicas da floresta de Broceliande, e tudo isto num departamento de Ciências Sociais. Depois da aula, o grupo o seguia até o café do prédio de História, onde se continuava a ouvir suas fabulações, as conceituações de fantástico, a organização (!!!) de sua visão de símbolo. E de tão forte mergulho no imaginário não poderia uma pessoa, de repente, se desligar e ir para casa dormir. Continuavam ecoando algumas das palavras, os princípios da "gramática" do fantástico: "Fantástico é onde os moinhos de vento não são gigantes", as urdiduras maliciosas do diable amoureux de Cazotte, os sucedidos do Manuscrito de Sarogoça de Jan Potocki.

\section{PORTAS ABertas}

Passei então a ser sua orientanda, e uma noite chego à sua casa na Rua Escobar Ortiz. Portas abertas. (Segundo ele, um assalto era estatisticamente improvável, desde que 99\% das casas da rua já tinham sido assaltadas.) Sobre uma cadeira de veludo cotelé amarela, já meio gasta como convém aos veludos, as mãos, os olhos apertados, o paletó de tweed, e a voz que conseguia reunir os objetos menos pensáveis, em associações inusitadas, dos artífices e vidreiros franceses do art-nouveau aos cararbas negros, às práticas da couvade. Eu sentada ao seu lado, de vez em quando me distraía olhando debaixo das portas, procurando cantinhos para ver se, para além do gato que lhe roçava as pernas, poderiam surgir dali alguns minúsculos gnomos, serezinhos fantásticos, em seu habitat natural. Mas eu sabia que aquele homem era capaz de tirar do bolso Os Mabinogion (epopéia dos celtas) e discorrer sobre ela sem titubeios, descrevendo, na memória que reinventa, um dos seus herois, fazendo-o vivo e encaixado num dos elos de sua fala; e nos passar o encantameno da antropologia pelos ensaios de Mauss - o ensaio sobre a Dádiva, de que gostava tanto; de entender como ninguém os princípios ritualísticos de uma Jessie Weston no seu From ritual to romance a que me introduziu.

\section{MEMÓRIA SOBRE MEMÓRIA}

Ruy Coelho, a própria oralidade viva, a memória projetando sempre a nova criação. Ele era todo o dizer, como se seu pensar se desenrolasse num tal ritmo, que não poderia caber na mancha gráfica das páginas, como se a ordenação convencional ferisse os princípios daquele eterno fluir:

"O Conhecimento é a recuperação intacta de um dado da memória. A memória é trabalhada, sofre transformações. A memória que nós temos de um evento nunca pode ser a total recuperação daquele evento tal como ele se deu. A memória está sempre trabalhando este patrimônio, está alterando o passado de certa forma; e há um problema então em saber o que se tira do passado. 'Era feliz. Não sei. Fui outrora, agora'. Talvez toda La recherche du temps perdu esteja nestes versos de Fernando Pessoa”.

Proust, uma das suas paixões, o autor em que aquele fluxo desmedido achava abrigo. Assim, a linguagem, sua logica, os fundamentos de estudos de psicologia, o universo de Lucia, sua mulher, brotando, e reunindo-se aos novos conhecimentos, que lhe chegavam numa operação alquímica, e o resultado nunca foi pedante.

Ouvi-lo era um ato indispensável, e assim íamos seguindo os cursos sucessivos. Os temas costuravam-se uns aos outros e a Utopia era um dos nós, um dos apoios do edifí-

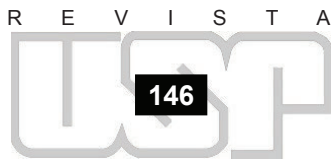


cio. Foi extraordinário, por exemplo, o curso em que passamos da Casa de Salomão de Francis Bacon à Voyage en Icarie de Cabet, acompanhando o ritmo da utopia, os impasses do homem e as saídas para enfrentá-los. Daí também brotavam jardins, fontes, cidades, a geometria do Paraíso, os vampiros, a science fiction, de Lovecraft a Silverberg. Dificilmente haverá em mãos tão lúcidas voz tão poética!

Lembro-me muito bem que um colega, nos corredores das "colméias", um dia falou:

- Que bom que vamos agora ouvir Ruy Coelho, o professor que mais ama literatura, enquanto outros tantos parecem mesmo odiá-la...

O fluxo de sua fala percorria os espaços e, de repente, pensávamos que as pessoas até podiam desaparecer, virar fantasmas ou bonecos mas, de fato, ao contrário, ele precisava delas, muito mais do que se podia crer, buscava sua ajuda para encontrar o elo na cadeia perdida, para com ele dar contas do "Benito Sereno" de Melville.

Disputava-se também, por isso, o prazer de levá-lo em casa, de enfrentar o trânsito em sua companhia. Tanto Teófilo Queiroz, seu amigo, como eu nos alternávamos nesta tarefa-glória. O carro, caixa de ressonância, fazia com que a cidade lá fora nem existisse. Era tempo de escuta que trazia algo de invenção, o comentário agudo que nos deixava aturdidos e fascinados.

\section{OS “ATRAPALHOS”}

Numa defesa de tese, das inúmeras de que participou, trazendo sempre o comentário instigante, dando o incentivo, o aplauso ou a compreensão das falhas, ao desfazer toda a tese de um candidato que argüía, perdido entre as páginas que se tinham descolado, embaralhado, dirige-se à platéia e comenta:

- Até que enfim consegui me encontrar. Risos das pessoas e a quebra do tom grave e enfatuado trazido por aquele ambiente solene. Assim, também o trocar de reuniões (tormento da vida universitária), o equívoco e o esquecimento de qual era mesmo aquela em que devia estar: "Pelas caras presentes é que recupero a reunião".

Aquela tarde de abril em São Paulo estava mais luminosa do que as outras. Uma luz de Lisboa na primavera. Alguns amigos e poucos colegas se encontrando na "Consolação" para a despedida de Ruy Coelho.

Chega então uma amiga e nos conta da última visita que ela lhe fizera: ele já desfigurado, sem forças e, de repente, perguntaram-lhe sobre os últimos acontecimentos do país, sobre os impactos do plano econômico aturdidor. Eis que retoma aquela força e nele se instala toda a velha magia. As mãos recomeçam o bailado, os olhos brilham, o discurso flui: - Estou aqui tentando discernir os limites da catástrofe. Estava lançado o mote.
- As citaços entre aspas correspondem a trechos de aulas de R. C.

\section{Excertos}

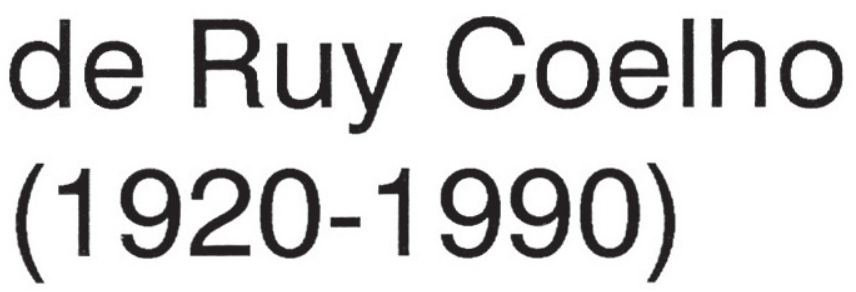

Apresentação de DECIO DE ALMEIDA PRADO

Como exemplo das preocupaçôes e do estilo de Ruy Coelho transcrevemos a seguir algumas páginas, entre as muitas que escreveu. $O$ primeiro trecho, extratdo do ensaio "Marcel Proust e a nossa época", saiu na revista Clima, no 1, maio de 1941. Era a sua estréia em letra de forma, aos vinte anos de idade. $O$ segundo trecho reproduz a parte introdutória do seu
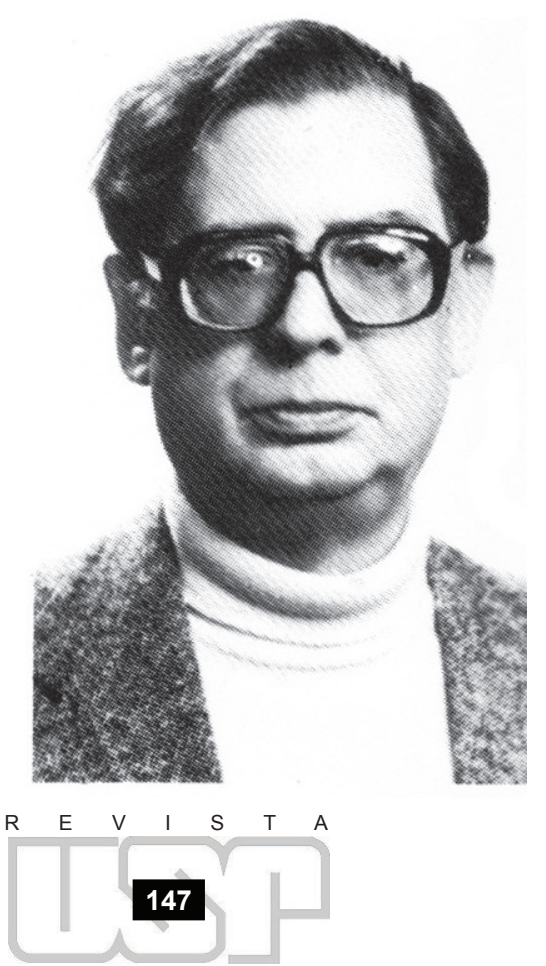